\title{
Units of phonological recoding of word-like stimuli used by children and adults
}

\author{
LESLIE J. CAPLAN \\ University of Iowa, Iowa City, Iowa 52240
}

\begin{abstract}
Third-grade, sixth-grade, and college-age subjects performed a "same".-"different" task, using a phonological identity criterion for visually presented pseudowords. Consistent with Krueger's (1978) model of single-glance "same"-"different" judgments, judgments of phonologically matching stimuli were made more quickly and less accurately than were judgments of phonologically nonmatching stimuli, and error rates and RTs were longer for phonologically similar nonmatching pairs than for phonologically dissimilar nonmatching pairs. It was concluded that subjects of all ages tested could process phonologically recoded information in a holistic fashion, and the implications of these conclusions with respect to reading processes are discussed.
\end{abstract}

In recent years, many investigators in the fields of cognition, perception, and reading have attempted to identify the units of word perception, and to determine whether those units change as a function of age or reading skill. Developmental data tend to support the hypothesis that younger or unskilled readers process words in smaller units than do older or more skilled readers. Early support for this proposal came from studies of eye movements in reading (Tinker, $1958,1965)$. In these studies, older readers tended to make fewer fixations per line than younger readers, suggesting that more skilled readers are able to "take in" larger stimulus units.

More recently, developmental investigations of word perception have yielded results suggesting that by the time children reach the fourth grade or so, they are able to process words and word-like stimuli in the larger units used by adults. Target-letter search studies indicate that by this age children locate letters faster when they are embedded in words or pseudowords than when they are embedded in orthographically irregular nonwords (Juola, Schadler, Chabot, \& McCaughey, 1978; Krueger, Keen, \& Rublevich, 1974). Similarly, Santa (1976-1977) studied the response times of second and fifth graders deciding whether target words contained probes consisting of one letter, two letters, or the entire word. An interaction between reading ability and probe type revealed that the use of the initial two-consonant cluster as a unit increased with reading ability. In addition,

This article is based on a dissertation submitted in 1980 to the Department of Psychology, University of Iowa, in partial fulfillment of the requirements for a doctoral degree. The author would like to thank Paul Davis and the third and sixth grade teachers at Horn Elementary School for their support and cooperation. Requests for reprints should be sent to: Leslie J. Caplan, Department of Psychological Science, Ball State University, Muncie, Indiana 47306. when Stanovich, West, and Pollak (1978) had subjects from third grade, sixth grade, and college search for an instance of a semantic category or for one of a set of three possible targets, search through lists of orthographically regular stimuli led to the fastest search times for subjects of all three age groups. Finally, Samuels, LaBerge, and Bremer (1978) had subjects from second grade, fourth grade, sixth grade, and college perform a semantic category judgment task, and found that RT increased as a function of word length only for subjects in the two youngest groups.

Although the results of these studies suggest that older subjects are more likely than younger subjects to process orthographically regular stimuli as units, the underlying strategy remains unspecified. Given the fact that orthographic regularity and pronounceability are inevitably confounded, one possibility is that developmental "unit" changes may be of phonological origin. That is, it is possible that as children become more skilled readers, they tend to phonologically recode larger stimulus units (e.g., words or syllables), rather than smaller units (e.g., letters or spelling patterns), as they read. Such a difference would tend to lead to faster, more effortless phonological recoding of orthographically regular material in skilled readers and to more painstaking, serial "sounding out" of such material in unskilled readers. Similarly, older readers would be expected to process orthographically regular stimuli more quickly than orthographically irregular stimuli, since orthographically regular stimuli could be phonologically recoded in larger units than orthographically irregular stimuli. Younger readers, on the other hand, would demonstrate no processing time advantage for orthographically regular stimuli, since they would rely on smaller units during the course of phonological recoding, regardless of the nature of the stimulus material. 
One experimental paradigm that is appropriate for the investigation of developmental changes in the unit of phonological recoding is the "same"-"different" response-time task. Results from a number of studies suggest that when some higher order code on which holistic processing may be based is available, "same" judgments are made more quickly than "different" judgments, but that when such a code is not available, this response-time relationship is not obtained. The response-time advantage for "same" judgments has been obtained for judgments based on qualitative, but not for those based on quantitative, aspects of nonlinguistic stimuli (Bindra, Donderi, \& Nishisato, 1968), for words and orthographically legal letter strings, but not for orthographically illegal letter strings (Barron \& Pittenger, 1974), and for judgments of acoustic and semantic, but not visual, identity of word pairs (Cohen, 1968). The results of these studies are consistent with the hypothesis that holistic processing of stimulus material leads to a responsetime advantage for "same" judgments in a "same""different" task.

A number of theorists have suggested that this response-time difference between "same" and "different" judgments is due to different types of processing underlying the two responses (e.g., Bamber, 1969; Klatzky \& Thompson, 1975; Pachella \& Miller, 1976; Silverman, 1973; Tversky, 1969). More recently, however, Krueger (1978) has proposed a more complete model of "same".-"different" judgments which can account for this set of findings. Although originally proposed as a model for perceptual judgments, it adapted easily to provide the theoretical framework used here. The model provides predictions for response-time and accuracy results of "same""different" judgments, both for displays which contain more material than can be perceived in a single glance (multiglance patterns) and for displays that can be perceived in a single glance. According to the model, subjects making "same"'-"different" judgments of multiglance patterns rely on a serial scanning strategy in which the contents of a single glance provide the units of comparison. "Different" judgments would be made more quickly than "same" judgments when multiglance stimuli are involved, since all elements of both patterns would have to be compared in a serial fashion before arriving at a "same" decision.

However, when the pattern is such that it can be perceived in a single glance, Krueger suggests that the subject relies on holistic processing. In this case, though, processing is complicated by the existence of internal noise in the system, which affects performance by increasing the apparent number of differences between two stimuli, and by creating variability in the apparent number of differences observed in both matching and nonmatching stimulus pairs. In- dividuals faced with such a task base their judgments on the number of mismatching features they observe between two stimuli, and two different criteria are used. If the number of observed differences (termed the difference count) falls below the "same" criterion level, the subject responds "same," and if it exceeds the "different" criterion, he responds "different." If, however, the difference count lies between the two criterion levels, then further holistic checks or "passes" are made, and the difference count is incremented in a cumulative fashion over passes. As a result, the incidence of false "different" responses is greater than that of false "same" responses. Krueger has also suggested that the existence of internal noise and consequent increase in the number of spuriously mismatching features would lead to a positive skew in the difference count distribution for matching stimuli, resulting in a positive shift for the "different" criterion. Rechecking would therefore occur more frequently for nonmatching stimuli than for matching stimuli, resulting in faster RTs for "same" than for "different" judgments.

The present investigation used the Krueger model to distinguish between holistic and serial processing of phonological information in visually presented pseudowords in readers of different ages. A "same""different" task involving a phonological identity criterion was used, but the task was modified slightly due to evidence in the developmental literature that young children's understanding of the terms "same" and "different" may be different from that of adults (Blake \& Beilin, 1975; Donaldson \& Wales, 1970; Gibson, Gibson, Pick, \& Osser, 1962). In addition, in order to ensure that subjects were basing their judgments on phonological, not visual, stimulus features, phonologically matching stimulus pairs half the time consisted of pseudowords that were visually identical and half the time of homophones.

The basic prediction, derived from the Krueger (1978) model, was that "same"'-"different" judgments of phonologically matching stimuli would be made more quickly and less accurately than those of phonologically nonmatching stimuli if subjects were older, more skilled readers, since these subjects would be expected to process the phonological information in the stimuli holistically. On the other hand, since younger, less skilled readers would presumably be less likely to use holistic processing, and would therefore rely on serial processing, the multiglance aspect of the model predicted that their "same" RTs would exceed their "different" RTs. Finally, as a further test, the degree of phonological similarity of pairs of nonmatching stimuli was manipulated. According to the single-glance aspect of the model, pairs of phonologically similar nonmatching stimuli should lead to longer RTs than should pairs of phonologically dissimilar nonmatching stimuli, since 
similar stimuli are more likely to yield difference counts falling between the two criteria. In addition, since "same" judgments are presumed to be based on difference counts that are low, but not usually zero, similar nonmatching stimuli were predicted to be judged to match more frequently than dissimilar nonmatching stimuli.

\section{METHOD}

\section{Subjects}

Subjects were drawn from each of three age groups. Sixteen adult (college age) subjects participated in order to fulfill a course requirement. Third- and sixth-grade subjects were volunteers from the Iowa City public school system, and were pretested on the Wide Range Achievement Test (WRAT) reading subtest (Jastak \& Jastak, 1978). Standard scores on this subtest have a mean of 100 and a standard deviation of 15 . Of the original sample of 20 third graders, children with WRAT reading standard scores of 130 or more $(n=4)$ did not participate in the experimental task. Similarly, of an original sample of 19 sixth graders, children with scores below $80(n=1)$ or above $125(n=2)$ were excluded from participation. The remaining sample of 16 third graders had a mean standard score of 118.6 (range $=104-129$ ), and the remaining 16 sixth graders had a mean standard score of 115.8 (range $=$ 100-123).

\section{Apparatus}

Using a slide projector equipped with an electrically operated shutter, stimuli were projected onto a screen set up approximately $46 \mathrm{~cm}$ from the subject. The stimuli were presented in uppercase, and subtended $5.0 \times 2.6 \mathrm{deg}$ of visual angle. The luminance of the screen was approximately $140 \mathrm{~cd} / \mathrm{m}^{2}$.

The subjects responded by depressing one of two labeled response keys, and the response ("yes" or "no") and latency (msec) were recorded.

The sequence of stimulus presentation and the recording of responses and response times were controlled by a Massey Dickinson digital logic system.

\section{Procedure}

Third and sixth graders were tested during two sessions in a trailer set up on school grounds. The first session consisted of the administration of the Wide Range Achievement word-recognition subtest and of pretraining on the experimental task. During the second session, the children performed the actual experimental task. College students performed the same pretraining and experimental task as described below in a single 40 -min session.

First session. During the first part of this session, the children were administered the Wide Range Achievement reading subtest. They then were pretrained on a task almost identical to the experimental task, with the exception that four-letter, one-syllable real words were used instead of pseudowords. In order to ensure that subjects could read them, the words were first presented one at a time, on cards, and the subjects were asked to pronounce them. If a word was mispronounced, the experimenter corrected the subject, and that word was re-presented after the entire set had been read. This process was continued, if necessary, until all of the words had been pronounced correctly one time.

The subjects were instructed that they would be seeing a series of two-word sequences. They were informed that on each trial they were to decide as fast and as accurately as possible whether the second word presented would sound exactly like the first (the target) if the two were to be pronounced aloud, and to press the "yes" key if this were the case and the "no" key otherwise. They were explicitly informed that stimuli that rhymed, but that were not phonologically identical should lead to "no" responses, and that stimuli that sounded exactly alike would not always be spelled alike. To ensure that all subjects understood these two aspects of the instructions, they were asked to produce instances of rhyming words and of homonyms. If they failed to do so, the experimenter provided instances, using simple onesyllable words.

There was a total of 24 pretraining trials, half of which were "yes" trials. Within each of the "yes" and "no" trial sets, half of the targets were HERE and half were TAIL. Within the set of "yes" trials, half of the second-presented stimuli were homonyms of the target (i.e., HEAR, TALE), and half were physically identical. Within the set of "no" trials, half of the foils rhymed with the target (i.e., YEAR, MAIL), and half did not (i.e., DOOR, WILL). Position (right or left) of the "yes" key was counterbalanced across subjects, and stimulus pairs from the conditions were presented in random order.

The events of each trial occurred in the following sequence. (1) The experimenter said, "first one," and initiated the trial. (2) The target word appeared for $2 \mathrm{sec}$. (3) The screen went blank for $1.5 \mathrm{sec}$. (4) The second stimulus appeared, and remained in view until the subject responded. (5) If the subject made an error, a $1,000-\mathrm{Hz}$ tone sounded.

The first session lasted approximately $15 \mathrm{~min}$.

Second session. At the beginning of this session, the instructions given for pretraining were repeated briefly, and the subjects were informed that the "rules" remained the same for this session, with the exception that the stimuli would be nonsense words (words the experimenter had "made up"). As in the pretraining procedure, the subjects first read aloud the stimuli to be used, rereading stimuli that had been earlier mispronounced, until each pseudoword had been correctly pronounced once.

Following 24 practice trials, there was a total of 192 experimental trials. The 192 experimental trials were divided into three trial blocks of 64 trials each; each trial block contained a full replication of the experiment. For both practice and for the experimental trials, all experimental conditions of the same level were represented equally often and in random order. Half of the trials were "yes" trials, and half were "no" trials. Within each of these trial sets, half of the targets were BAFE and half were KAlL. Of the "yes" trials, half of the second-presented stimuli were homophones of the target (i.e., BAIF, KALE), and half were physically identical to it. Of the "no" trials, half of the foils rhymed with the target (phonologically similar pairs) and half did not (phonologically dissimilar pairs). Phonological and visual similarity values used for the foils had previously been obtained by collecting ratings, using a 9-point scale, from an independent group of adult subjects. Foils in the similar condition (mean phonological similarity $=6.22$, mean visual similarity $=3.89$ ) were closely equated in visual similarity to those in the dissimilar condition (mean phonological similarity $=3.10$, mean visual similarity $=3.88$ ). The stimuli used, along with their similarity values, are presented in Table 1.

Two different sets of foils were used in the "no" condition, and these sets were counterbalanced across subjects. Trial blocks were presented in one of two orders, counterbalanced across subjects, as was whether the right or left response key was the "yes" key. For those subjects who participated in two sessions, the same key was used for "yes" responses in both sessions.

The sequence of events occurring during a trial was the same as that which had occurred during pretraining. Response times were recorded from the onset of the second stimulus.

\section{RESULTS}

The analyses reported below were performed only on data from the 192 experimental trials, excluding trials on which mechanical errors occurred or on which response times either exceeded $4,000 \mathrm{msec}$ or were below $100 \mathrm{msec}$. For both response times and 
Table 1

Mean Phonological and Visual Similarity Values and Standard Errors of the Estimate for Pseudoword Pairs

\begin{tabular}{|c|c|c|c|c|}
\hline & \multicolumn{2}{|c|}{$\begin{array}{c}\text { Phonological } \\
\text { Similarity } \\
\end{array}$} & \multicolumn{2}{|c|}{$\begin{array}{c}\text { Visual } \\
\text { Similarity } \\
\end{array}$} \\
\hline & Mean & SE & Mean & $\mathrm{SE}$ \\
\hline & \multicolumn{4}{|c|}{ Target: KAIL } \\
\hline \multicolumn{5}{|l|}{ Second Pseudoword } \\
\hline \multicolumn{5}{|l|}{ Matching Trials } \\
\hline Same Spelling: KAIL & 8.65 & .35 & 9.00 & .00 \\
\hline Different Spelling: KALE & 8.82 & .13 & 6.76 & .43 \\
\hline \multicolumn{5}{|l|}{ Nonmatching Trials } \\
\hline \multicolumn{5}{|l|}{ Stimulus Set A } \\
\hline Similar Sound: FALE & 6.59 & .38 & 3.76 & .44 \\
\hline Dissimilar Sound: NAYT & 3.12 & .44 & 3.76 & .50 \\
\hline \multicolumn{5}{|l|}{ Stimulus Set B } \\
\hline Similar Sound: NALE & 7.06 & .28 & 4.41 & .54 \\
\hline \multirow[t]{2}{*}{ Dissimilar Sound: MAIF } & 2.94 & .39 & 4.31 & .35 \\
\hline & \multicolumn{4}{|c|}{ Target: BAFE } \\
\hline \multicolumn{5}{|l|}{ Second Pseudoword } \\
\hline \multicolumn{5}{|l|}{ Matching Trials } \\
\hline Same Spelling: BAFE & 8.88 & .12 & 8.70 & .21 \\
\hline Different Spelling: BAIF & 8.47 & .31 & 5.65 & .51 \\
\hline \multicolumn{5}{|l|}{ Nonmatching Trials } \\
\hline \multicolumn{5}{|l|}{ Stimulus Set A } \\
\hline Similar Sound: PAIF & 6.00 & .51 & 3.59 & .46 \\
\hline Dissimilar Sound: NALE & 2.65 & .42 & 3.53 & .38 \\
\hline \multicolumn{5}{|l|}{ Stimulus Set B } \\
\hline Similar Sound: LAIF & 6.06 & .43 & 2.94 & .36 \\
\hline Dissimilar Sound: BAWT & 2.94 & .40 & 2.94 & .30 \\
\hline
\end{tabular}

errors, separate analyses were conducted to compare matching and nonmatching trials and to compare similar and dissimilar nonmatching trials. Analyses of matching trials were also conducted in order to investigate the role of visual identity in these trials.

\section{Matching and Nonmatching Trials}

These two analyses were conducted in order to test the prediction that response times would be shorter and error rates higher on trials involving phonologically matching rather than nonmatching stimulus pairs. The results of these analyses are presented in Table 2; the major findings are presented in the columns labeled "Overall Yes" and "Overall No" in the "Phonologically Matching Trials" and "Phonologically Nonmatching Trials" sections, respectively.

Response times. A four-way mixed design analysis of variance was performed on individual subject mean correct RTs, with correct response ("yes" or "no"), trial block (first, second, or third), and target (BAFE or KAIL) as within-subject factors, and age (third grade, sixth grade, or college) as the betweensubjects factor. Scores for the matching trials were collapsed across the two spelling conditions, and scores for the nonmatching trials were collapsed across the two similarity conditions.

The predicted age $\times$ response interaction failed to

Table 2

Mean Response Time (RT, in Milliseconds) and Error Rate (ER, in Percentages) as a Function of Correct Response, Age, Trial Block, and Visual or Phonological Similarity

\begin{tabular}{|c|c|c|c|c|c|c|c|c|c|c|c|c|}
\hline \multirow[b]{3}{*}{ Grade } & \multicolumn{6}{|c|}{ Phonologically Matching Trials } & \multicolumn{6}{|c|}{ Phonologically Nonmatching Trials } \\
\hline & \multicolumn{2}{|c|}{$\begin{array}{l}\text { Visually } \\
\text { Identical } \\
\end{array}$} & \multicolumn{2}{|c|}{$\begin{array}{l}\text { Visually } \\
\text { Different }\end{array}$} & \multicolumn{2}{|c|}{$\begin{array}{l}\text { Overall } \\
\text { "Yes" }\end{array}$} & \multicolumn{2}{|c|}{$\begin{array}{c}\text { Phonologically } \\
\text { Similar } \\
\end{array}$} & \multicolumn{2}{|c|}{$\begin{array}{c}\text { Phonologically } \\
\text { Dissimilar }\end{array}$} & \multicolumn{2}{|c|}{$\begin{array}{c}\text { Overall } \\
\text { "No" }\end{array}$} \\
\hline & RT & ER & RT & ER & $\mathbf{R T}$ & ER & RT & ER & RT & ER & RT & ER \\
\hline & \multicolumn{12}{|c|}{ Trial Block 1} \\
\hline $\begin{array}{l}\text { Third } \\
\text { Sixth } \\
\text { College } \\
\text { Combined }\end{array}$ & $\begin{array}{r}1049.0 \\
711.9 \\
540.5 \\
767.1\end{array}$ & $\begin{array}{l}3.6 \\
5.0 \\
3.6 \\
4.0\end{array}$ & $\begin{array}{r}1012.7 \\
709.3 \\
555.7 \\
759.3\end{array}$ & $\begin{array}{l}4.4 \\
3.6 \\
2.4 \\
3.4\end{array}$ & $\begin{array}{r}1031.9 \\
718.9 \\
548.0 \\
766.3\end{array}$ & $\begin{array}{l}3.9 \\
4.3 \\
2.9 \\
3.7\end{array}$ & $\begin{array}{r}1095.2 \\
724.4 \\
593.7 \\
804.4\end{array}$ & $\begin{array}{l}4.4 \\
4.6 \\
2.4 \\
3.8\end{array}$ & $\begin{array}{r}1020.9 \\
722.1 \\
573.0 \\
772.0\end{array}$ & $\begin{array}{r}.8 \\
3.6 \\
.4 \\
1.6\end{array}$ & $\begin{array}{r}1058.5 \\
725.0 \\
582.9 \\
788.8\end{array}$ & $\begin{array}{l}2.7 \\
4.1 \\
1.4 \\
2.7\end{array}$ \\
\hline Combined & \multicolumn{12}{|c|}{ Trial Block 2} \\
\hline $\begin{array}{l}\text { Third } \\
\text { Sixth } \\
\text { College } \\
\text { Combined }\end{array}$ & $\begin{array}{l}924.8 \\
709.3 \\
526.3 \\
720.1\end{array}$ & $\begin{array}{l}4.3 \\
3.9 \\
2.4 \\
3.5\end{array}$ & $\begin{array}{l}956.2 \\
713.5 \\
547.5 \\
739.1\end{array}$ & $\begin{array}{l}3.9 \\
2.7 \\
1.6 \\
2.7\end{array}$ & $\begin{array}{l}939.4 \\
712.5 \\
540.3 \\
730.8\end{array}$ & $\begin{array}{l}4.1 \\
3.3 \\
2.0 \\
3.1\end{array}$ & $\begin{array}{l}968.2 \\
733.3 \\
554.9 \\
752.1\end{array}$ & $\begin{array}{r}3.6 \\
2.0 \\
.8 \\
2.0\end{array}$ & $\begin{array}{l}991.6 \\
726.8 \\
525.6 \\
748.0\end{array}$ & $\begin{array}{r}2.0 \\
.4 \\
1.2 \\
1.2\end{array}$ & $\begin{array}{l}988.3 \\
732.0 \\
540.3 \\
753.5\end{array}$ & $\begin{array}{l}2.7 \\
1.2 \\
1.0 \\
1.6\end{array}$ \\
\hline Combined & \multicolumn{12}{|c|}{ Trial Block 3} \\
\hline $\begin{array}{l}\text { Third } \\
\text { Sixth } \\
\text { College } \\
\text { Combined }\end{array}$ & $\begin{array}{l}900.0 \\
670.9 \\
503.5 \\
691.5\end{array}$ & $\begin{array}{r}3.6 \\
4.6 \\
.8 \\
2.4\end{array}$ & $\begin{array}{l}938.9 \\
707.7 \\
539.5 \\
728.7\end{array}$ & $\begin{array}{l}2.0 \\
2.8 \\
2.0 \\
2.8\end{array}$ & $\begin{array}{l}918.1 \\
690.7 \\
521.6 \\
710.1\end{array}$ & $\begin{array}{l}2.7 \\
3.7 \\
1.4 \\
2.6\end{array}$ & $\begin{array}{l}983.0 \\
697.8 \\
541.9 \\
740.9\end{array}$ & $\begin{array}{r}2.0 \\
2.4 \\
.8 \\
1.6\end{array}$ & $\begin{array}{l}954.5 \\
690.2 \\
519.7 \\
721.5\end{array}$ & $\begin{array}{r}.8 \\
1.6 \\
1.2 \\
1.2\end{array}$ & $\begin{array}{l}969.4 \\
694.0 \\
530.8 \\
731.4\end{array}$ & $\begin{array}{l}1.4 \\
2.0 \\
1.0 \\
1.4\end{array}$ \\
\hline Combined & \multicolumn{12}{|c|}{ Collapsed Across Trial Blocks } \\
\hline $\begin{array}{l}\text { Third } \\
\text { Sixth } \\
\text { College } \\
\text { Combined }\end{array}$ & $\begin{array}{l}957.9 \\
697.4 \\
523.4 \\
726.2\end{array}$ & $\begin{array}{l}3.8 \\
4.6 \\
2.2 \\
3.6\end{array}$ & $\begin{array}{l}969.3 \\
710.2 \\
547.6 \\
742.3\end{array}$ & $\begin{array}{l}3.4 \\
3.0 \\
2.0 \\
2.8\end{array}$ & $\begin{array}{l}963.2 \\
707.4 \\
536.6 \\
735.7\end{array}$ & $\begin{array}{l}3.6 \\
3.8 \\
2.1 \\
3.2\end{array}$ & $\begin{array}{r}1015.4 \\
718.5 \\
563.5 \\
765.8\end{array}$ & $\begin{array}{l}3.2 \\
3.0 \\
1.3 \\
2.5\end{array}$ & $\begin{array}{l}989.3 \\
713.0 \\
539.4 \\
747.2\end{array}$ & $\begin{array}{r}1.2 \\
1.8 \\
.9 \\
1.3\end{array}$ & $\begin{array}{r}1005.4 \\
717.0 \\
551.3 \\
757.9\end{array}$ & $\begin{array}{l}2.3 \\
2.4 \\
1.2 \\
2.0\end{array}$ \\
\hline
\end{tabular}


reach significance at the $p<.05$ level. "Yes" responses were, however, generally made more quickly than "no" responses, as reflected by a main effect of response $[F(1,45)=7.23, p=.010]$. Older subjects' response times were also significantly lower than younger subjects' $[F(2,45)=23.53, p<.001]$. In addition, response times decreased over the course of the experimental session, as indicated by a significant effect of trial block $[F(2,90)=10.03, p<.001]$. Finally, a significant, but basically irrelevant, interaction between target and age was obtained $[F(2,45)=6.15, p=.004]$. All remaining main effects and interactions failed to reach significance at the $p<.05$ level.

Errors. An analogous analysis was performed on the number of errors made by the subjects, using the same factors as those used in the response-time analysis reported above. The prediction that more errors would be committed on matching trials than on nonmatching trials was confirmed $[\mathrm{F}(1,45)=9.21, \mathrm{p}=$ $.004]$. Errors also decreased over trial blocks $[F(2,90)$ $=4.11, \mathrm{p}=.020 \mathrm{]}$. In addition, the interaction between target, response, and trial block was significant $[\mathrm{F}(2,90)=3.21, \mathrm{p}=.045]$. All remaining main effects and interactions failed to reach significance at the $p<.05$ level.

\section{Matching Trials}

The next two analyses were performed on data from trials on which "yes" was the correct response, primarily to determine whether subjects had used visual identity information strategically. These results are also presented in Table 2; the major results are presented in the "Phonologically Matching Trials" section of the table.

Response times. A four-way mixed design analysis of variance was performed on individual subject mean correct RTs, with spelling (same as or different from the target), trial block, and target as withinsubject factors, and age as the between-subjects factor. Response times were faster when the two pseudowords were spelled the same (mean $=726.2 \mathrm{msec}$ ) than when they were spelled differently (mean = $742.3 \mathrm{msec})[\mathrm{F}(1,45)=5.69, \mathrm{p}=.021]$. This main effect, however, was modified by an interaction between trial block and spelling $[\mathrm{F}(2,90)=3.24, \mathrm{p}=$ .044]. A series of follow-up tests revealed that the difference in RT between the two spelling conditions failed to reach significance in the first and second trial blocks, but that RTs for physically identical stimulus pairs were lower than those for physically nonidentical pairs in the third trial block $[F(1,45)=$ $8.91, \mathrm{p}=.005]$.

In addition to these findings, response times decreased with age $[F(2,45)=21.87, p<.001]$ and over trial blocks $[F(2,90)=7.25, p=.001]$. The interaction between age and trial block was also significant
$[F(4,90)=2.80, p=.031]$. No other main effects or interactions were significant at the $\mathrm{p}<.05$ level.

Errors. The numbers of incorrect responses made by each subject on matching trials were also subjected to an analysis of variance, using the same factors as those used in the response-time analysis for matching trials. None of the main effects or interactions resulting from this analysis reached significance at the $\mathrm{p}<.05$ level.

\section{Nonmatching Trials}

In order to test the prediction that phonologically similar nonmatching stimulus pairs would lead to longer RTs and higher error rates than phonologically dissimilar pairs, the last two analyses were performed on data from trials on which "no" was the correct response. The results of these analyses are presented in Table 2, and the major findings are presented in the "Phonologically Nonmatching Trials" section of the table.

Response times. Individual subject mean correct RTs were subjected to a four-way mixed design analysis of variance, using the same factors as those used to analyze matching trial data, with the exception that similarity of nonmatching pairs was substituted for the spelling factor. Response times were marginally longer for similar pairs than for dissimilar pairs $[F(1,45)=3.07, p=.086]$. Response time also decreased with age $[F(2,45)=23.45, p<.001]$ and over trial blocks $[F(2,90)=7.72, p=.001]$. All remaining main effects and interactions failed to reach significance at the $\mathrm{p}<.05$ level.

Errors. The number of trials on which subjects incorrectly responded "yes" was subjected to an analysis of variance identical in design to that performed on response times from nonmatching trials. As was originally predicted, more errors were made on similar than on dissimilar pairs $[F(1,45)=7.96$, $\mathrm{p}=.007]$. Errors also decreased over trial blocks $[F(2,90)=3.13, p=.049]$, although this effect appeared to be more marked for one of the targets, as indicated by a significant target $\times$ trial block interaction $[\mathrm{F}(2,90)=3.53, \mathrm{p}=.034]$. All remaining main effects and interactions failed to reach significance at the $\mathrm{p}<.05$ level.

\section{DISCUSSION}

In general, the results of this study are consistent with the predictions made on the basis of Krueger's (1978) single-glance model. The following discussion will begin with a summary of the major results and a consideration of their implications, including a section in which the unexpected failure to find the predicted age effects is discussed. Finally, a number of theoretical issues will be considered, including ques- 
tions of whether the stimuli used here may have violated the model's assumptions regarding homogeneity of sameness and difference, and possible alternative explanations of the obtained pattern of results.

\section{Major Results: Summary and Implications}

Matching vs. nonmatching trials: The effect of phonological identity. The most important prediction provided by the Krueger model was that "singleglance" or holistic processing should yield faster judgments on matching trials than on nonmatching trials. This prediction was confirmed: "yes" responses were made significantly more quickly than "no" responses, suggesting that "yes" judgments resulted from fewer holistic comparisons or "passes" than did "no" judgments. In addition, as predicted, more errors were made on phonologically matching trials than on phonologically nonmatching trials, a finding which supports the hypothesized effect of internal noise.

Nonmatching trials: The effect of phonological similarity. In contrast to the findings obtained from comparisons of "yes" and "no" responses, the results obtained with respect to the phonological similarity manipulation in nonmatching trials provided somewhat more ambiguous support for the original predictions. On the one hand, the error data from nonmatching trials do conform to predictions. Similar stimulus pairs did lead to higher error rates than did dissimilar stimulus pairs, which is consistent with the hypothesis that similar stimuli would yield difference counts below the "same" criterion level more frequently than would dissimilar stimuli. On the other hand, although mean response times for the similar pairs were longer than those for dissimilar pairs, the difference failed to reach significance at the traditional alpha level. A possible explanation of this negative result may lie in the fact that the stimuli were matched on a measure of visual similarity, thereby limiting the range of possible differences in phonological similarity.

Matching trials: The effect of visual identity. It is important to note that the relative roles of visual and phonological processing appeared to change over the course of the experimental session for subjects of all ages. During the first two trial blocks, when there were no significant differences between RTs for homophones and for visually identical stimulus pairs, the fact that "yes" judgments were made more quickly than "no" judgments was likely to have been the result only of differences in phonological processing. However, by the third trial block, the subjects responded more quickly when the two pseudowords were visually identical than when they were homophones. This difference suggests that, by this time, the subjects were using visual information strategi- cally, perhaps by testing for visual identity before testing for phonological identity. Therefore, the fact that "yes" judgments were made more quickly than "no" judgments in this trial block may be due to the fact that phonological processing, which presumably requires more time than visual processing, may have occurred more frequently on phonologically nonmatching trials than on phonologically matching trials. Whether such a strategy change replaced a purely phonological strategy or coexisted with it in some way cannot be determined on the basis of the present results. The fact that the difference in response times between "yes" and "no" responses remains virtually identical across the three trial blocks (see Table 2) makes any conjecture regarding strategy change particularly difficult. Nevertheless, it does appear that at least during the course of the first two trial blocks, the subjects did respond on the basis of comparisons of phonological information.

A comparison of children and adults: An unexpected similarity. The major finding that children functioned very much like adults was clearly unexpected, since most developmental studies of word perception have indicated that holistic word processing strategies tend to become more prevalent as children grow older (e.g., Juola et al., 1978; Krueger et al., 1974; Samuels et al., 1978). One possible explanation for the lack of age trends obtained here is that the use of relatively short letter strings precluded finding any evidence of serial processing in younger subjects. Silverman (1973), for example, using adult subjects, found that "same".-"different" judgments of digit strings five digits long or shorter yielded faster "same" than "different" judgments, whereas the reverse RT pattern was obtained for strings that were six to eight digits long. Findings like these have been used to support the hypothesis that, in adults, shorter strings are processed as units, but that longer strings are processed in a serial fashion. However, findings from other studies using other paradigms, but more wordlike stimuli, have yielded mixed results in investigations of the effects of word length for subjects of different ages. For example, Juola et al. (1978), using string lengths ranging from three to five letters, reported that target-letter search time increased linearly with string length for subjects from kindergarten through college, whereas Krueger et al. (1974), using string lengths ranging from three to six letters, reported an effect of string length only in younger subjects and not in adults. It appears, therefore, that the choice to use shorter letter strings here, in order to decrease the amount of pronunciation training necessary and simplify obtaining judgments of visual and phonological similarity among stimuli, may possibly have influenced the results. The possible effect of increased word length is, however, an empirical question that should be addressed in the near future. 
In addition, the particular characteristics of the children sampled here may have resulted in adultlike performance by subjects of all ages. One of the more obvious possibilities is that the relatively advanced reading abilities of the children included in this sample were the result of word processing skills which may involve many of the same processes required by this task. This may be particularly true in light of the fact that the younger children used here were already close to the age at which word-superiority effects are first reported; it is possible that younger or less advanced children would yield the predicted pattern of results. The second possible explanation lies in the methods by which these children were being taught to read. The school from which they were sampled does emphasize holistic word recognition in reading, and aspects of this training may have transferred to the task used here.

Finally, the apparent conflict that exists between the results of the present study and those of previous investigations of the units of word perception in children could well be the result of important differences in the tasks used. The major difference, of course, is that the task used here required the subject to engage in phonological recoding, whereas the role of phonological recoding in the tasks used in other studies is unclear. That is, since most tasks emphasize the processing of visual characteristics of stimuli, usually by requiring some type of visual search, the possible use of phonological information may have varied between or within subjects. The requirement of the present study that subjects respond on the basis of the sound of the entire stimulus, rather than on the basis of some visual component of the stimulus, such as the identification of individual letters would require, may have encouraged subjects to process the stimuli holistically. Smith and Spoehr (1974) have suggested that such task differences, that is, between emphasis on processing an entire stimulus or its component parts, may lead to apparent differences in processing strategies in adults. That is, tasks that emphasize identification or processing of the stimulus as a whole tend to yield results indicative of holistic processing, whereas tasks involving processing of individual constituents tend to yield results indicative of serial processing. If this task difference is indeed the major one that distinguishes this study from earlier ones, then it may be true, despite the alternative explanations discussed above, that once individuals of any age or skill level are capable of forming phonological representations of printed material, the manner in which they process those representations remains relatively constant across age.

\section{Theoretical Considerations}

It should also be noted that, despite the difficulties posed by many of the methodological problems discussed above, the Krueger model still seems to provide a plausible and parsimonious explanation of this body of results. Nickerson (1978) has proposed a number of artifactual explanations that may account for the typical "same"-"different" response-time difference, all of which appear to be implausible here. The first is that, typically, specific "same" pairs occur more frequently than do specific "different" pairs, resulting in a stimulus sampling bias that did not exist in the present study. Secondly, he suggests that stimulus priming may lead to this type of result, but is less likely to occur when the two stimuli are separated by several seconds, as they were here. Finally, the suggestion that subjects may have some type of response bias favoring "same" responses is inconsistent with the fact that false "no" responses occurred more frequently than false "yes" responses. In addition, most of Nickerson's three theoretical hypotheses are consistent to some extent with various aspects of the Krueger model: trace strength, confirmation checking, and independent processes.

Homogeneity of sameness and difference. It was particularly fortunate that the present results were generally predicted by the Krueger (1978) model, since no a priori attempts were made to control for heterogeneity of sameness or difference. The original model made the assumption that the actual number of mismatching features remained constant among nonmatching stimuli, and Krueger (1979) has suggested that when the number of possible mismatching features varies considerably, the resulting "different" difference count distribution becomes more variable. Under such conditions, the response time advantage for "same" judgments may decrease or disappear. Given that pairs of nonmatching stimuli used here differed in their degrees of phonological similarity, and that matching stimulus pairs did not, one might have expected to find results suggestive of a more heterogeneous set of "different" stimulus pairs. Fortunately, however, this possible difference in variability does not appear to have been the case: The response-time advantage for judgments of matching stimuli, coupled with a higher error rate for judgments of these stimuli, suggests that the "different" difference count distribution was not more variable than the "same" distribution.

On the other hand, it might be argued that the obtained pattern of RTs and error rates resulted from another artifact, a "same" distribution more variable than the "different" distribution. Such a situation would correspond to Krueger's (1978) Case 1, which yields the same predictions that the model used originally to predict these results, Krueger's Case 6, does. Although the phonological similarity values do not appear to follow this type of pattern, inspection of the visual similarity values for the stimulus 
pairs used reveals that matching stimuli varied more in visual similarity than did nonmatching stimuli. This heterogeneity among matching pairs, however, does not seem to have had a major impact on the pattern of results, as indicated by two sets of observations. First, as discussed above, the fact that visually identical matching pairs and visually nonidentical matching pairs led to essentially the same RTs during the first two trial blocks suggests that subjects were relying on phonological, not visual, information in making their judgments throughout most of the experimental session. Second, if the two levels of matching stimuli resulted in a more heterogeneous stimulus set than did the two levels of nonmatching stimuli, then one might expect a greater difference in RTs and errors between the two levels of matching stimuli than between the two levels of nonmatching stimuli. This appears not to have been the case: Although the two levels of matching stimuli differ significantly only in RT, the two levels of "different" stimuli differed only in errors. There does not seem, therefore, to be any strong evidence to suggest any extreme differences in heterogeneity between matching and nonmatching stimuli, in either direction.

Alternative explanations. Even though the Krueger single-glance model appears to predict the present results very well, it may be argued that the adequacy of this study as a test of holistic processing rests on the assumption that the Krueger model is correct, and that any of a number of alternative explanations might suffice. For example, a simpler explanation of the differences obtained between "yes" and "no" judgments than that proposed by Krueger is the possibility of a speed-accuracy tradeoff (Pachella, 1974). Although the RTs and error rates for matching and nonmatching trials appear to follow this type of pattern, the fact that the response time and error analyses comparing these conditions did not yield identical results tends to decrease the plausibility of this hypothesis. In particular, the fact that the two analyses led to different significant interactions suggests that a speed-accuracy tradeoff would not be an especially convincing explanation of these results.

It might, however, still be maintained that the pattern of findings obtained here may not have resulted from holistic processing. Although this is true, the Krueger model is not the only basis for suggesting that this pattern of RTs is the result of such processing. The fact that "same" judgments are apparently made more quickly than "different" judgments only in those tasks in which higher order codes exist for the stimuli, as discussed earlier, provides indirect support for the conclusions made here. Also, as mentioned earlier, a number of other theorists have proposed dual process models, in which "same" judgments result from holistic processing and "different" judgments from serial processing, to explain the fre- quent finding that "same" judgments are made more quickly than "different" judgments (e.g., Bamber, 1969; Klatzky \& Thompson, 1975; Tversky, 1969). The major advantage of the Krueger model is the fact that it provides a means by which error, as well as $\mathrm{RT}$, predictions can be made. The fact that the RT results obtained here appear to be the result of holistic processing, as suggested by a number of investigators and theorists, and that errors also conform to Krueger's predictions suggests that holistic processing may indeed have occurred.

\section{Conclusions}

In general, then, the results of the present investigation of the effects of phonological identity and similarity on response times and error rates suggest that individuals of all groups tested were able to process phonologically recoded information in a holistic fashion. Whether or not individuals of all ages spontaneously form such representations, however, may be what differentiates younger from older readers. To the extent that the present study forced all subjects to form phonological representations of the stimuli, subjects of all age groups apparently dealt with those representations in a holistic fashion. If, however, younger children do not typically make use of phonological information spontaneously, or do not use it holistically, then one might expect them to deal with stimuli in a serial fashion, which is, in fact, what most other investigators have reported. To a certain extent, then, this study appears to have been a "competence," rather than a "performance," investigation: It demonstrated young readers' apparent ability to deal with phonologically recoded information in a holistic fashion, but revealed little about whether they spontaneously process sound information holistically when they are not forced to do so.

In addition, whether or not this ability to engage in holistic processing is reflected in how children actually read remains an open question. This investigation, like most studies of word perception, revealed little about how people process information during the actual reading process. More ecologically valid investigations of this latter type would provide logical and useful follow-ups to the research presented here. In addition, replication of this study with younger or less advanced readers may yield more useful information regarding developmental trends in the ability to recode and process phonological information holistically.

\section{REFERENCES}

BAMBER, D. Reaction times and error rates for "same-different" judgments of multidimensional stimuli. Perception \& Psychophysics, 1969, 6, 169-174.

Barron, R. W., \& Pittenger, J. B. The effect of orthographic 
structure and lexical meaning on "same-different" judgments. Quarterly Journal of Experimental Psychology, 1974, 26, 566581.

Bindra, D., Donderi, D. C., \& Nishisato, S. Decision latencies of "same" and "different" judgments. Perception \& Psychophysics, 1968, 3, 121-130.

Blake, J., \& Bellin, H. The development of same and different judgments. Journal of Experimental Child Psychology, 1975, 19, 177-194.

Cohen, G. A comparison of semantic, acoustic, and visual criteria for matching of word pairs. Perception \& Psychophysics, 1968, 4, 203-204.

Donaldson, M., \& Wales, R. On the acquisition of some relational terms. In J. R. Hayes (Ed.), Cognition and the development of language. New York: Wiley, 1970.

Gibson, E. J., Gibson, J. J., Pick, A. D., \& Osser, H. A developmental study of the discrimination of letter-like forms. Journal of Comparative and Physiological Psychology, 1962, 55, 897906.

Gibson, E. J., \& Levin, H. The psychology of reading. Cambridge, Mass: M.I.T. Press, 1975.

Jastak, J. F., \& Jastak, S. The Wide Range Achievement Test: 1978 (Rev. ed.). Wilmington, Del: Jastak Associates, 1978.

Juola, J. F., Schadler, M., Chabot, R. J., \& McCaughey, $\mathbf{M}$. W. The development of visual information processing skills related to reading. Journal of Experimental Child Psychology, $1978,25,459-476$.

KLATzky, R. L., \& Thompson, A. Integration of features in comparing multifeature stimuli. Perception \& Psychophysics, 1975, 18, 428-432.

Kruegen, L. E. A theory of perceptual matching. Psychological Review, 1978, 85, 278-304.

KRUEGER, L. E. A model of unidimensional perceptual matching. Journal of Experimental Psychology: Human Perception and Performance, 1979, 5, 277-288.

Krueger, L. E., KeEn, R. H., \& Rublevich, B. Letter search through words and nonwords by adults and fourth grade children. Journal of Experimental Psychology, 1974, 102, 845-849.
Nickerson, R. S. On the time it takes to tell things apart. In J. Requin (Ed.), Attention and performance VII. Hillsdale, N.J: Erlbaum, 1978.

Pachella, R. G. The interpretation of reaction time in informationprocessing research. In B. H. Kantowitz (Ed.), Human information processing: Tutorials in performance and cognition. Potomac, Md: Erlbaum, 1974.

Pachella, R. G., \& Millen, J. O. Stimulus probability and same-different classification. Perception \& Psychophysics, 1976, 19, 29-34.

Samuels, S. J., LaBerge, D., \& Bremer, C. D. Units of word recognition: Evidence for developmental changes. Journal of Verbal Learning and Verbal Behavior, 1978, 17, 715-720.

SANTA, C. M. Spelling patterns and the development of flexible word recognition strategies. Reading Research Quarterly, 1976$1977,12,125-144$.

Silverman, W. P. The perception of identity in simultaneously presented complex visual displays. Memory \& Cognition, 1973, $1,459-466$.

Sмiтн, E. E., \& Spozhr, K. T. The perception of printed English: A theoretical perspective. In B. H. Kantowitz (Ed.), Human information processing: Tutorials in performance and cognition. New York: Wiley, 1974.

Stanovich, K. E., West, R. F., \& Pollak, D. The effect of orthographic structure on word recognition in a visual search task. Journal of Experimental Child Psychology, 1978, 26, 137 146.

Tinken, M. A. Recent studies of eye movements in reading. Psychological Bulletin, 1958, 55, 215-231.

Tinken, M. A. Bases for effective reading. Minneapolis: University of Minnesota Press, 1965.

Tversky, B. Pictorial and verbal encoding in a short-term memory task. Perception \& Psychophysics, 1969, 6, 225-233.

(Manuscript received March 30, 1981; revision accepted for publication August 4, 1981.) 